\title{
The analysis of temperature disintegration on the body of fuel injector during research on test bench
}

Article describes the results of researches fuel injectors on the test bench with using infrared camera. During researches has been verified various fuel injectors (working order and faulty). In results inner leaks fuel injectors have increased return dosages. Few elements influence on this. It is difficult to determine which element could be uses after disassemble. It is possible to determine the source of leaks during analysis decomposition of temperature fuel injector body.

Key words: infrared camera, Common Rail system injector, injection and return dosages, fuel high pressure pump, CI engines

\section{Introduction}

Using infrared camera by diagnosing Common Rail fuel injectors is innovative project and belongs to without invasion method of diagnostic. Without invasion method of diagnostic are effective, fast and not expensive. Normal diagnostic procedure of repairable injectors consists in disassemble and microscope researches. Microscope researches are very effective but time - consuming and expensive. This method is very helpful when it is noticeable that injector leaks but engineer is not sure where the leaks appear. It is possible to localize very fast damage area. There are many possibilities to use infrared camera to diagnose fuel system in CI - engines. It could be used to diagnose high pressure section in the fuel pump, adjusters and sensors, high pressure fuel pipes and rails. The good point of this type researches are short time and cheapness.

\section{Infrared camera as diagnosing tools CI - engine injection systems}

The main task of infrared camera is temperature measurement of researched object [7]. These type of researches are contactless and don't disrupt device work. So that it is very good diagnosing element. Temperature illustrates technical condition of device especially elements of fuel injection system such fuel pump or injectors [2]. The leakages on precision elements of injection system cause temperature rise. Main reason of faulty fuel injector work are leaks [3]. Injector during research on test bench heats up but in defect areas is very hot. Research protocol presents magnitude of injection and return dosages [4]. If dosages are wrong research worker don't know what is wrong. There are many elements in fuel injector which could be faulty. But when it is known the area of defect it could be very easy wrong element to diagnose. Defects of fuel injectors concern the precision elements and inner sealers usually. These parts are responsible for correct injector work. If something wrong is with these elements injectors dosages are wrong. The temperature on the injector body rise despite of leaks. When infra camera is used it could be easy find faulty elements because there will be higher temperature. Figure 1 presents electromagnetic Bosch fuel injector disassembly on spare parts. There are marked elements where temperature rises during leaks (A, B, C). Higher temperature occurs in injector coil because of work [5].

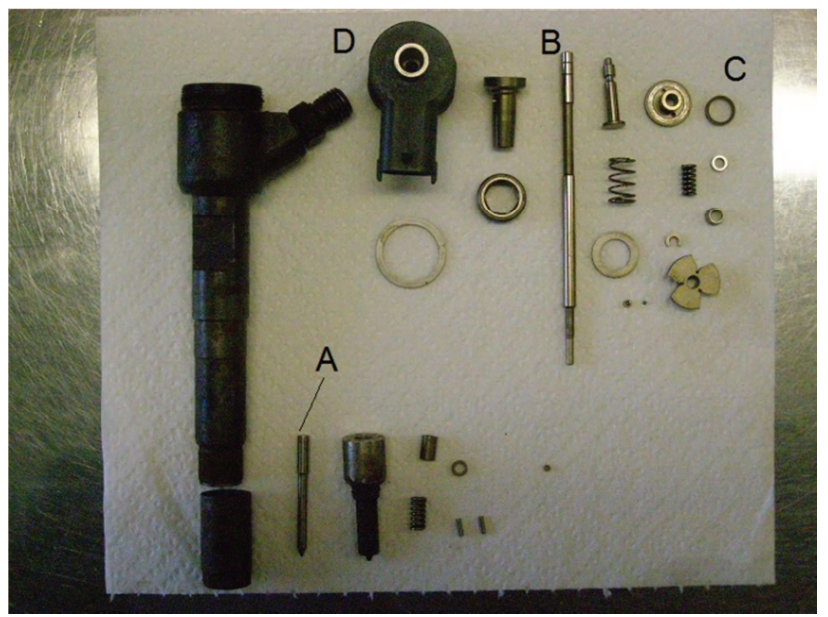

Fig. 1. Electromagnetic Bosch fuel injectors. A - precision element on injector needle, B - fuel injector steering valve, $\mathrm{C}$ - valve sealer, D - fuel injector coil

Figure 2 presents electromagnetic Bosch fuel injector researched infrared camera during test bench. There has been marked on the figure precision element on injector needle (A), fuel injector steering valve (B), valve sealer (C) and fuel injector coil (D). It is noticeable that higher temperature is on precision elements due to leaks and in the solenoid.

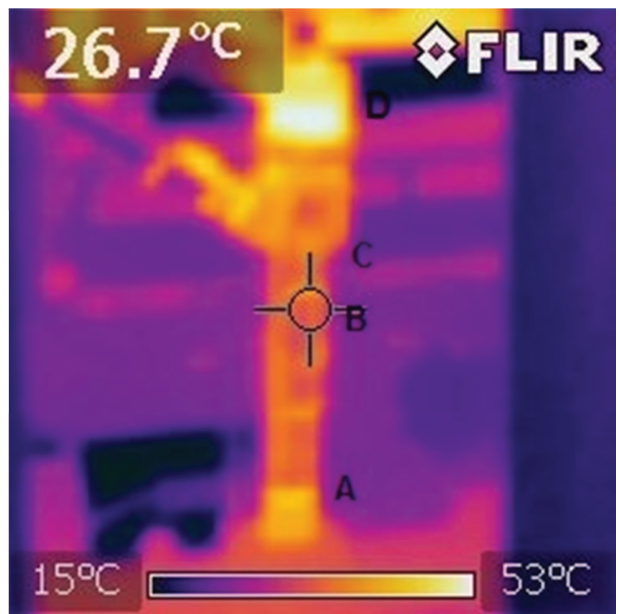

Fig. 2. Electromagnetic Bosch fuel injector on the infrared camera picture during test 
There is possibility to analysis temperature injected fuel (Fig. 3) using infrared camera. Fuel temperature influences on corrosion, cavitation, erosion and friction phenomena. This parameter could be useful to determine phenomena inside injector nozzle.

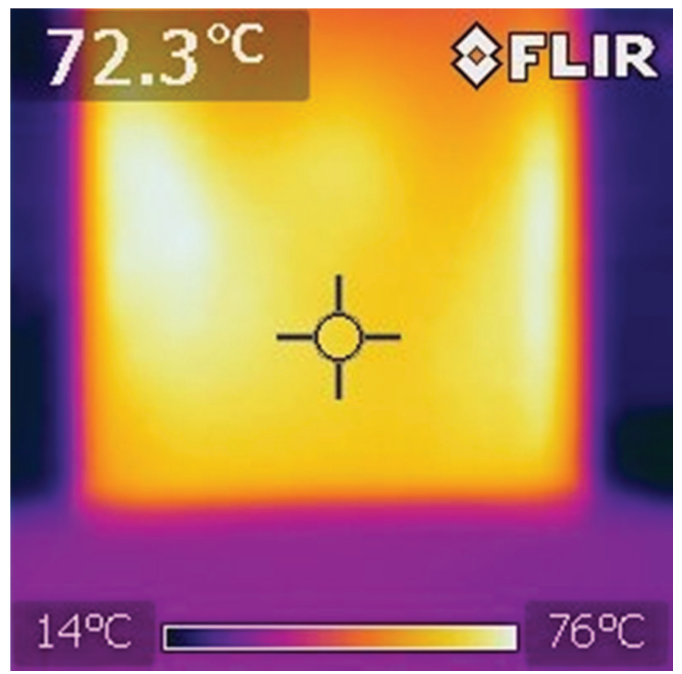

Fig. 3. Temperature of injection fuel

There is opportunity to research fuel injection pump especially high pressure section. If there are leaks it would be visible using infrared camera. Figure 4 presents the picture of high pressure injection pump during research on the bench.

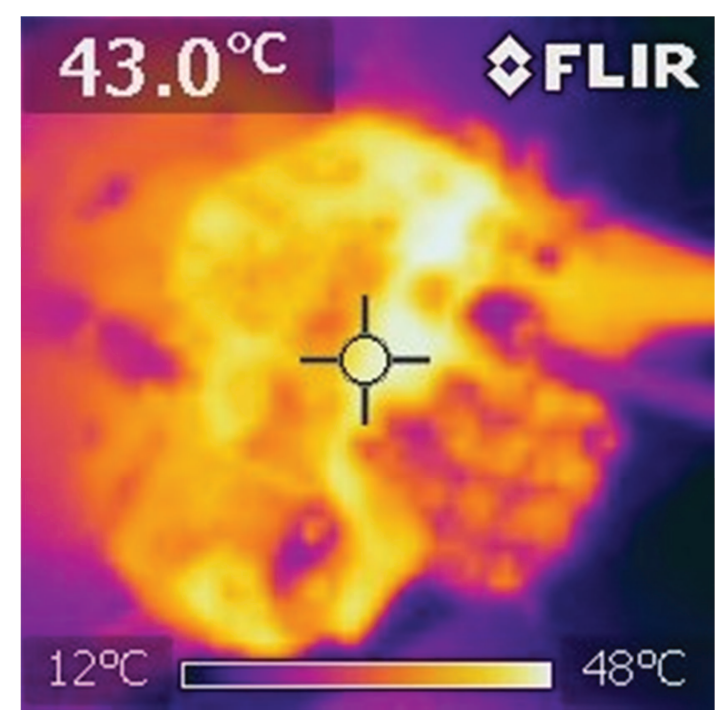

Fig.4. Temperature of fuel injection pump

\section{Laboratory test}

During laboratory tests has been used electromagnetic Delphi fuel injectors. Figure 5 presents researched injector disassembled on spare parts. There has been sectioned two areas. The first injector nozzle (A) and the second steering valve and electromagnetic coil areas (B). This areas determine fuel injector work parameters (injection and return dosages and injection delay). Catalogue number researched fuel injector were EJBR02201Z [6]. Researches has been made on STPiW 3 test bench (Fig. 7) by using infrared camera (Fig. 6). Infrared camera Flir i3 measures the temperatures $273-523 \mathrm{~K}\left(0-250^{\circ} \mathrm{C}\right)$. Measure deviation is $\pm 2^{\circ} \mathrm{C}$.

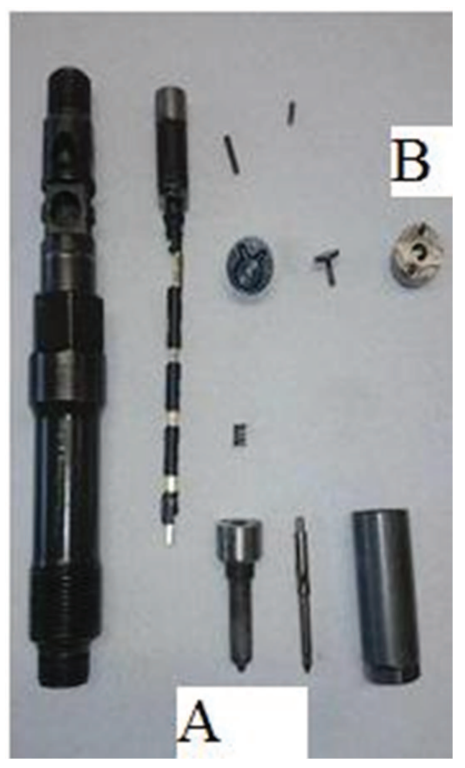

Fig. 5. Electromagnetic Delphi fuel injector dismantled on spare parts: A injector nozzle area, B - steering valve and electromagnetic coil area

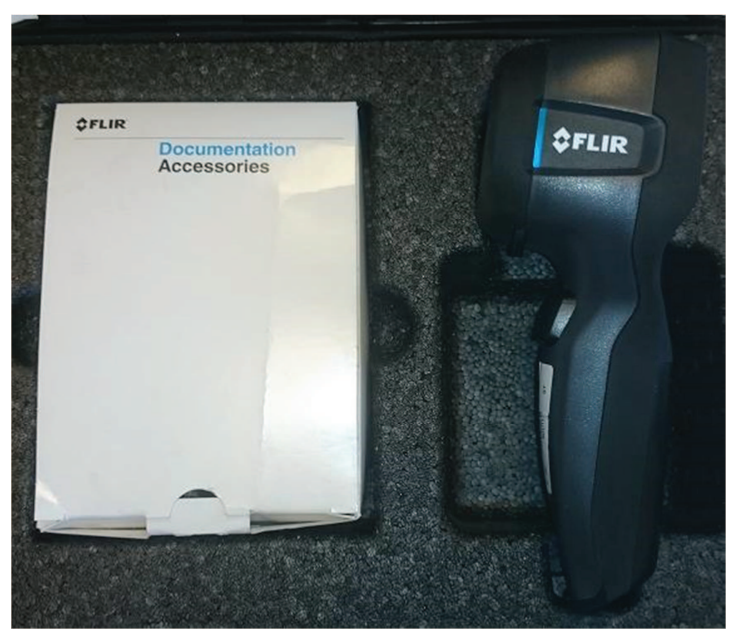

Fig. 6. Infrared camera Flir i3

Table 1 shows standard test of researched fuel injectors. There is noticeable that injectors 1 and 4 are damage. There are huge return dosages what influence on theirs parameters. Figure 7 presents test bench STPiW 3 with researched Delphi injectors and magnitude of return dosage test. There was taken two injectors third and fourth during researches with infrared camera. Studies has been taken into consideration two areas of injectors body nozzle (Fig. 8, 9) and steering valve with coil (fig. 10,11). Tests have been made with 50, 80, 110 and $140 \mathrm{MPa}$ system pressures. Figure 12 presents measured return dosage by pressure $140 \mathrm{MPa}$ for faulty and good working injectors. There is noticeable in all instances considerable difference temperatures between injectors. Figures 13 and 14 present damage fuel injector precision elements: needle and steering valve. 


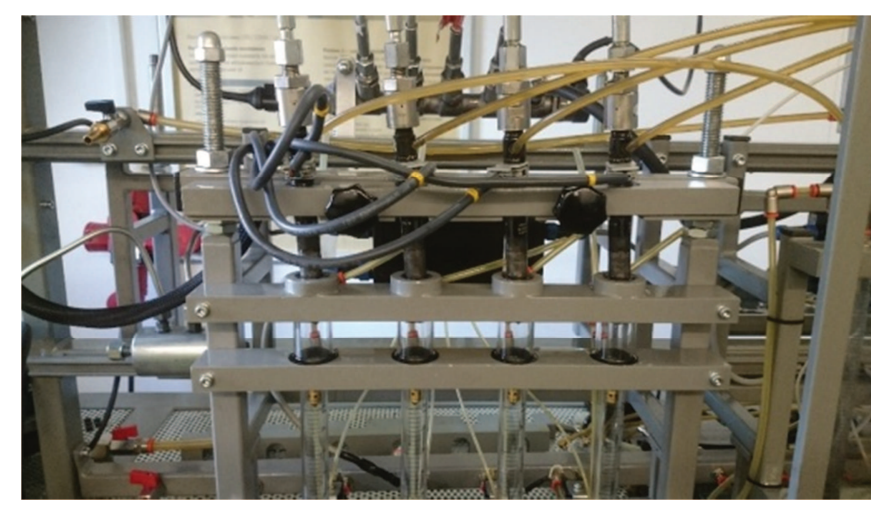

A

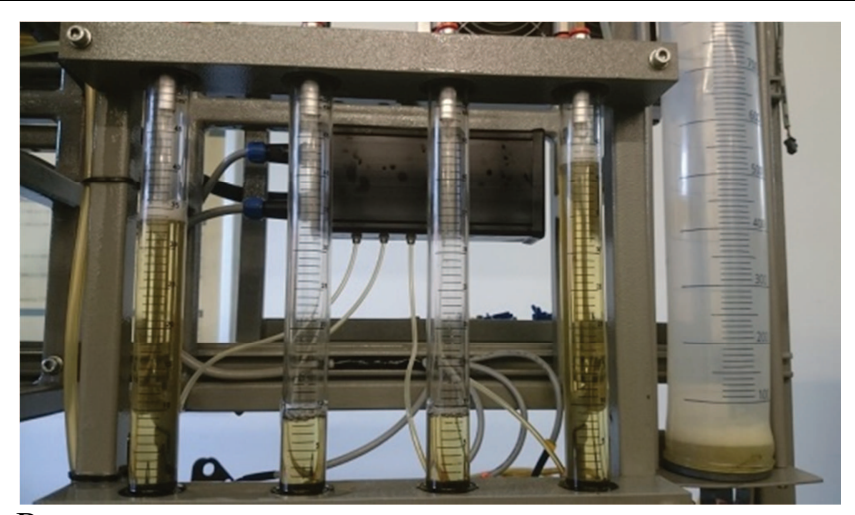

$\mathrm{B}$

Fig. 7. A - researched fuel injectors on test bench STPiW 3, B - the magnitudes of return dosages researched fuel injectors

Tab.1. Injection and return dosages standard test results

\begin{tabular}{|c|c|c|c|c|c|c|c|c|}
\hline No. & $\begin{array}{c}\text { Injection } \\
\text { pressure }[\mathrm{MPa}]\end{array}$ & $\begin{array}{l}\text { Injection } \\
\text { time }[\mu \mathrm{s}]\end{array}$ & & Range & Inj. 1 & Inj. 2 & Inj. 3 & Inj.4 \\
\hline \multirow{2}{*}{1} & \multirow{2}{*}{165} & 0 & Injection & $0.00-0.00$ & 0.0 & 0.0 & 0.0 & 0.0 \\
\hline & & $60 \mathrm{~s}$ & Return & $0.00-40.00$ & 110.23 & 32.97 & 33.86 & 112.74 \\
\hline \multirow{2}{*}{2} & \multirow{2}{*}{160} & \multirow{2}{*}{930} & Injection & $49.00-55.00$ & 39.8 & 53.21 & 54.11 & 40.40 \\
\hline & & & Return & $0.00-56.00$ & 111.30 & 36.18 & 38.26 & 119.40 \\
\hline \multirow{2}{*}{3} & \multirow{2}{*}{120} & \multirow{2}{*}{220} & Injection & $0.30-4.50$ & 6.3 & 1.85 & 2.06 & 9.6 \\
\hline & & & Return & $0.00-56.00$ & 81.08 & 33.10 & 35.32 & 87.23 \\
\hline \multirow{2}{*}{4} & \multirow{2}{*}{80} & \multirow{2}{*}{780} & Injection & $27.10-34.50$ & 31.00 & 30.10 & 27.80 & 31.80 \\
\hline & & & Return & $0.00-56.00$ & 79.23 & 31.76 & 33.42 & 82.34 \\
\hline \multirow{3}{*}{5} & \multirow{3}{*}{25} & \multirow{3}{*}{480} & Injection & $2.70-7.45$ & 3.80 & 3.80 & 3.60 & 4.20 \\
\hline & & & Return & $0.00-56.00$ & 42.70 & 10.86 & 14.97 & 58.60 \\
\hline & & & & Test pass & No & Yes & Yes & No \\
\hline
\end{tabular}

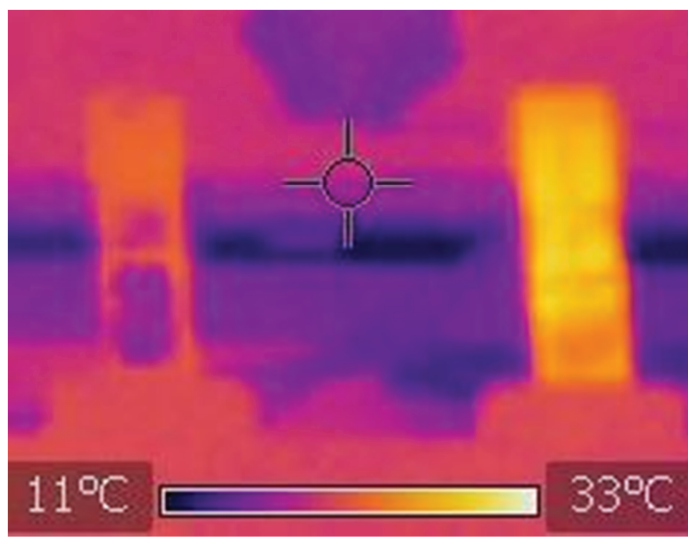

A

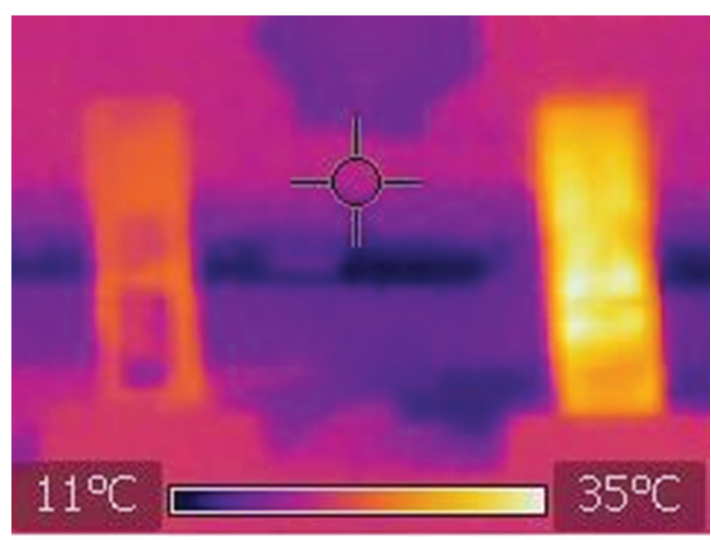

B

Fig. 8. Pictures of nozzle areas from infrared camera for third and fourth injectors: A - fuel pressure $50 \mathrm{MPa}$, B - fuel pressure $80 \mathrm{MPa}$

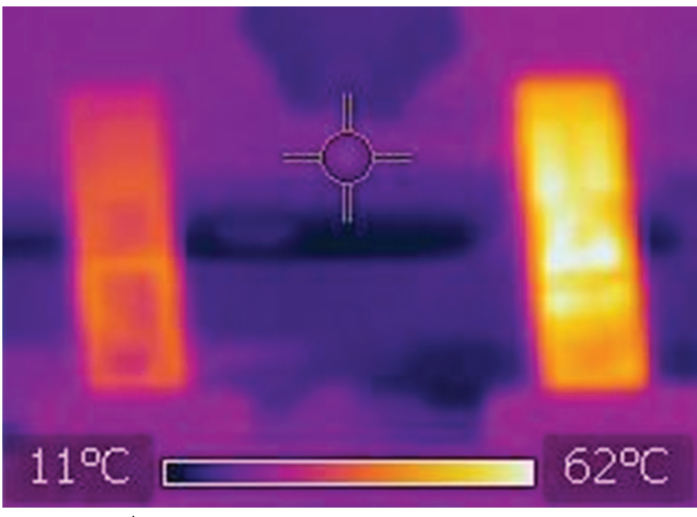

A

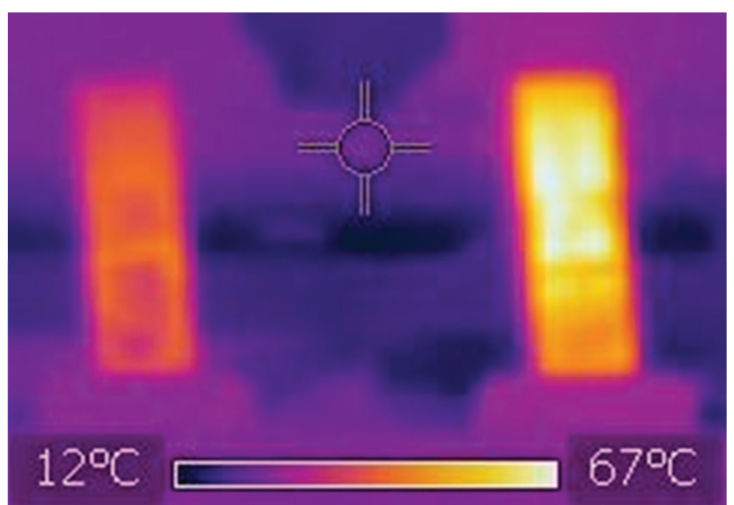

B

Fig. 9. Pictures of nozzle areas from infrared camera for third and fourth injectors: A - fuel pressure $110 \mathrm{MPa}, \mathrm{B}$ - fuel pressure $150 \mathrm{MPa}$ 

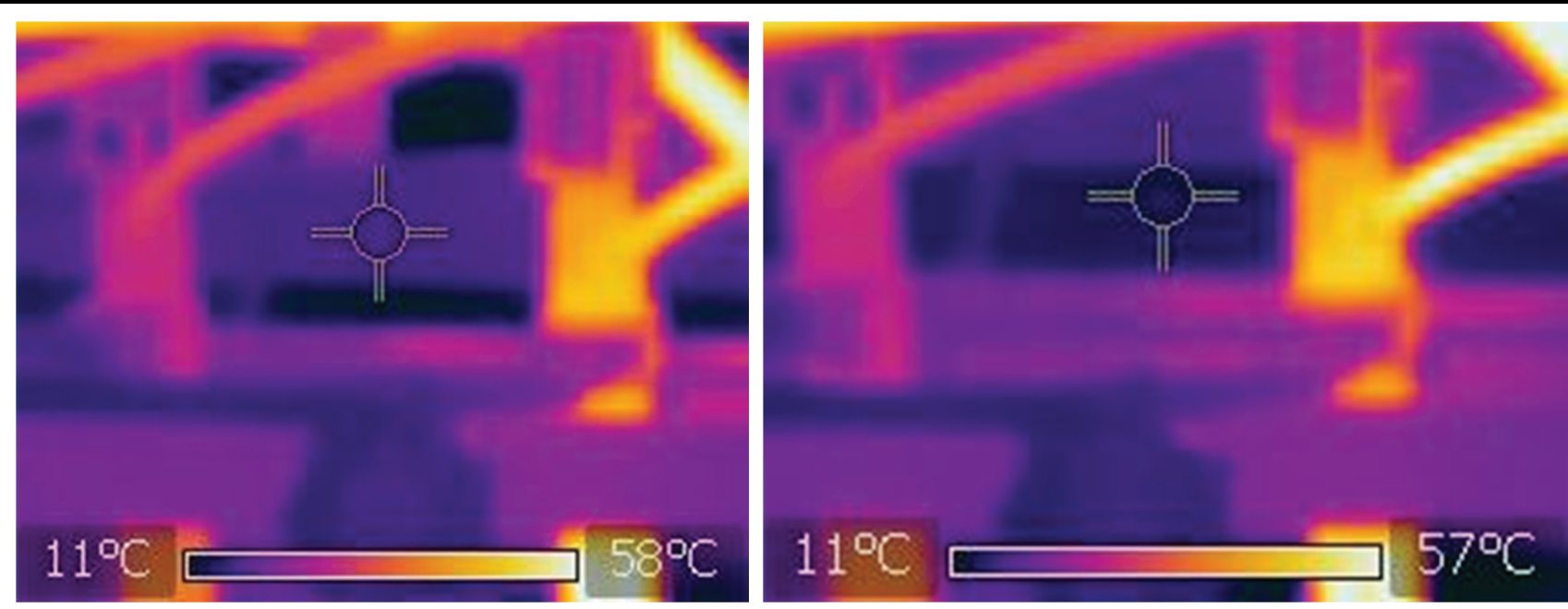

Fig. 10. Pictures of steering valve and electromagnetic coil areas from infrared camera for third and fourth injectors: A - fuel pressure $50 \mathrm{MPa}$, B - fuel pressure $80 \mathrm{MPa}$

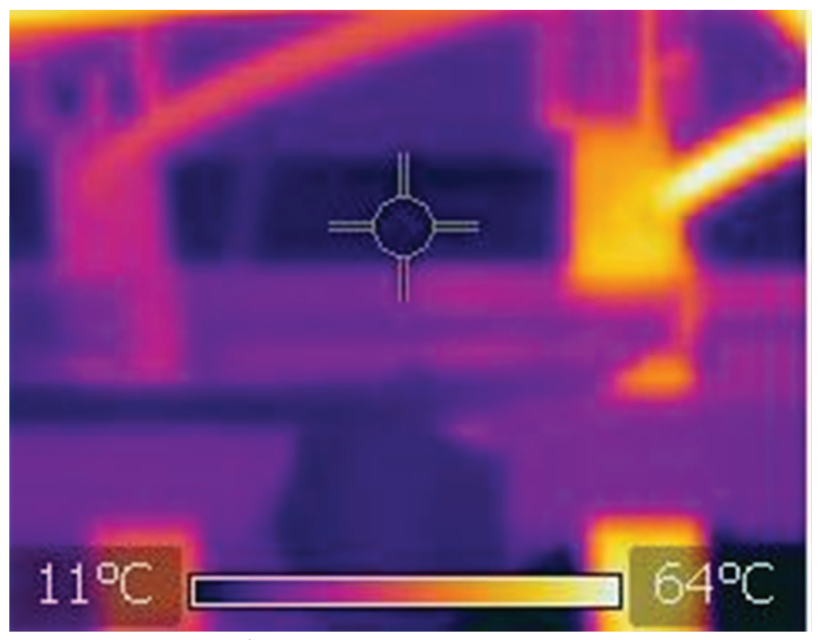

A

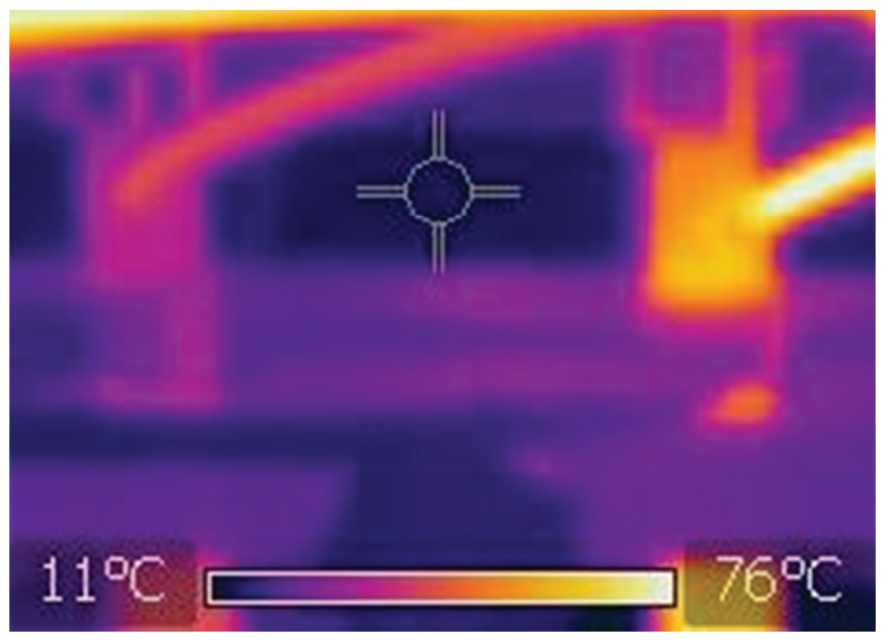

B

Fig. 11. Pictures of steering valve and electromagnetic coil areas from infrared camera for third and fourth injectors: A - fuel pressure $110 \mathrm{MPa}$, B - fuel pressure $140 \mathrm{MPa}$

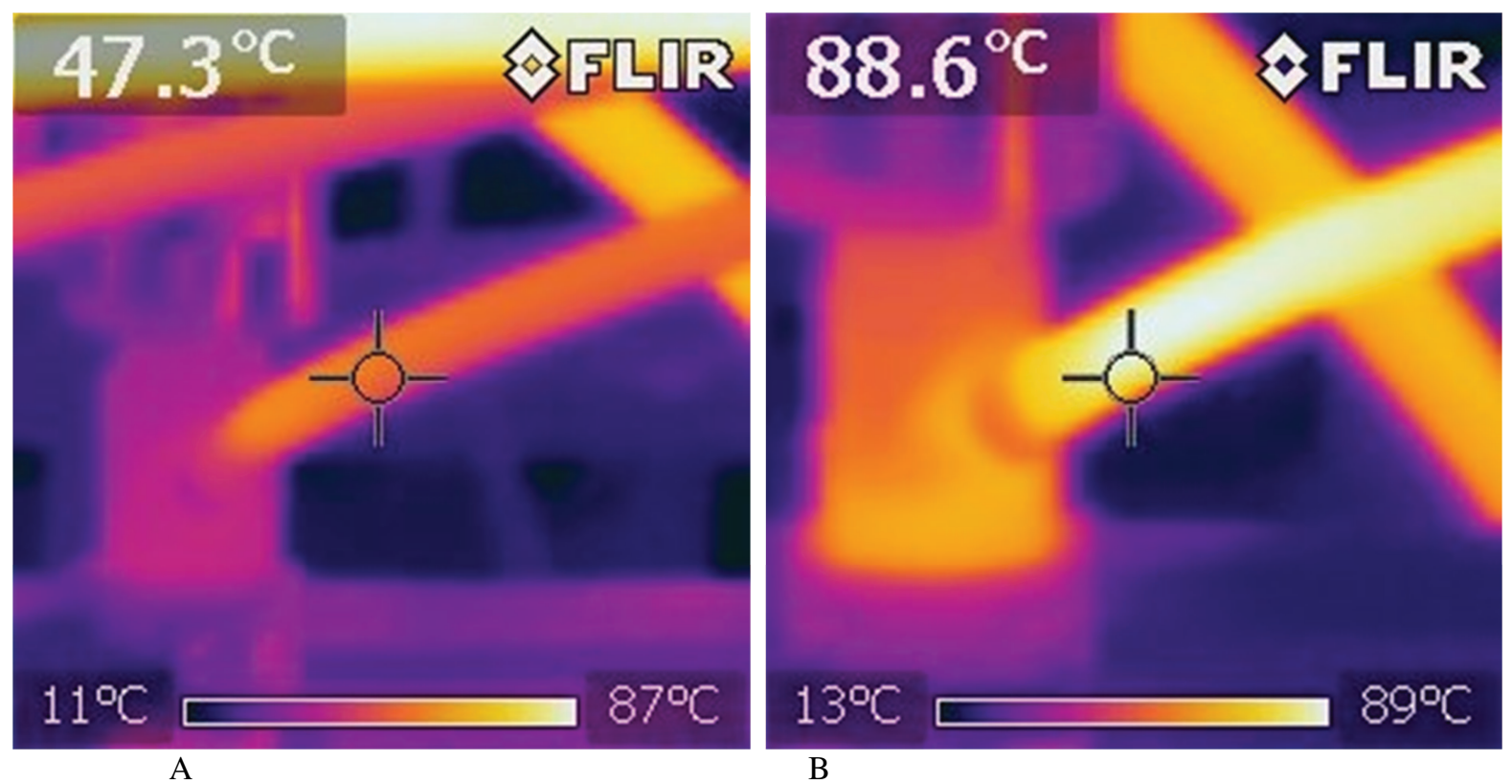

Fig. 12. Temperature of return dosage: A - correct fuel injector, B - faulty fuel injector 


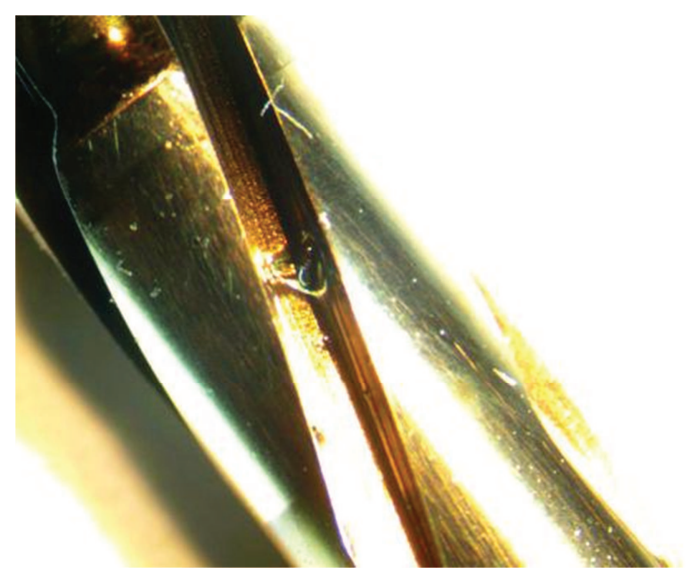

A

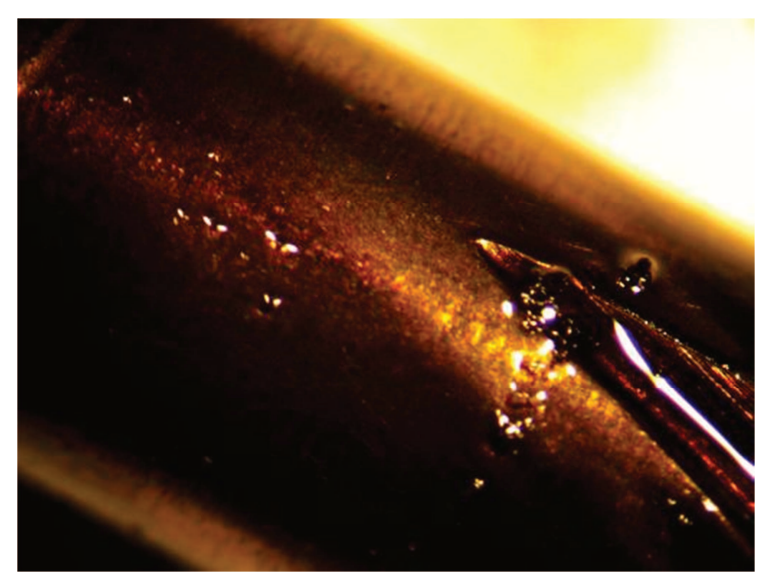

B

Fig. 13. A, B Precision elements on damage injector needle

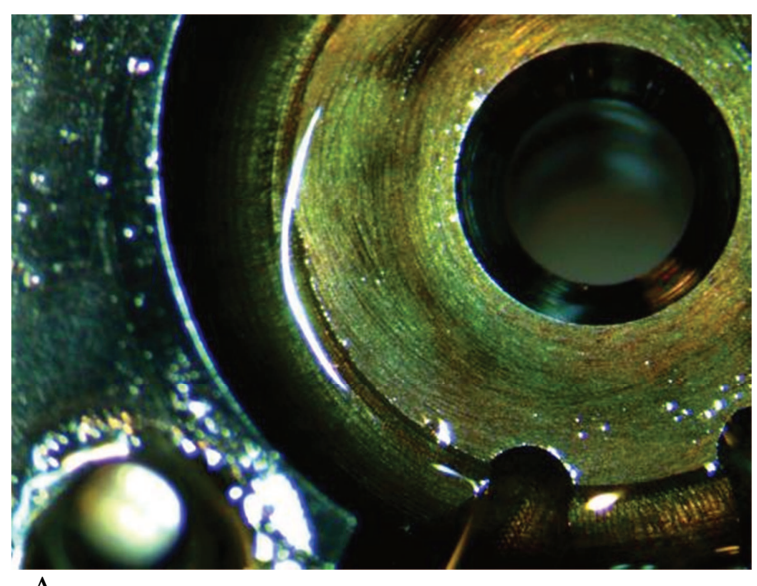

A

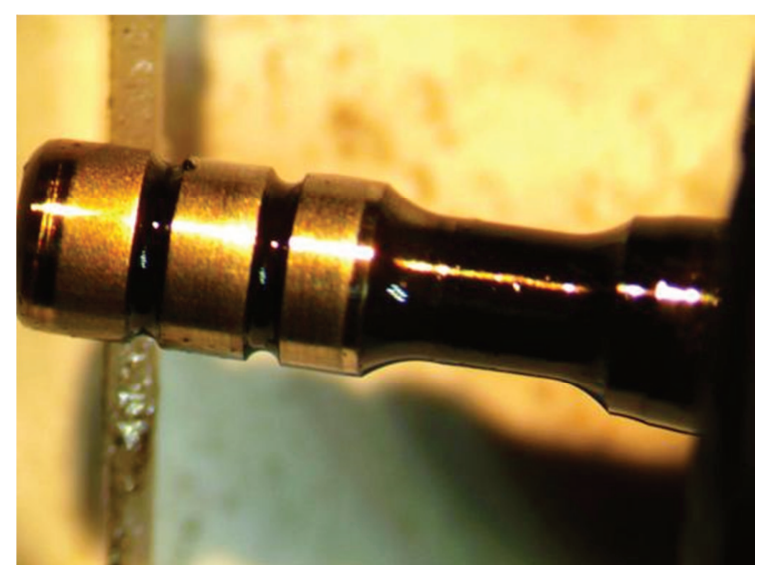

$\mathrm{B}$

Fig. 14. Damage injector steering valve $\mathrm{A}$ - valve section, $\mathrm{B}$ - piston

\section{Conclusion}

It is possible to state during analysis of research results that infrared camera could be useful during researches fuel injectors on the test bench. There happen very often that fuel injector is researched and the standard test shows its damage but engineer don't know where it occur. Fuel injector has few areas: nozzle with needle, steering valve with sealer and coil. When return dosage is to high it is hard to determine where the fault occurs. There is possibility to disassemble injector and use microscope to check precision elements but sometimes it is hard to find where the leaks are. It is easy to change all elements but then repair costs increase. Using infrared camera is very effective method without invasion of diagnostic during researches. There have been researched two areas of injectors during test. The first area was injector nozzle area. If the precision element on the injector needle is damage it will increase leaks. Temperature would be higher there (Fig. 8, 9). Infrared camera registers it. The same situation is with steering valve. Figure 12 presents the temperature difference between good working and faulty injectors. Return dosages amount $119.40 \mathrm{~mm}^{3} / \mathrm{H}$ for faulty fuel injector and 38.26 $\mathrm{mm}^{3} / \mathrm{H}$ for good working by $160 \mathrm{MPa}$ test pressure. This difference is visible on infrared camera because the faulty injector has temperature of returning fuel $88^{\circ} \mathrm{C}(361 \mathrm{~K})$ and good working $47^{\circ} \mathrm{C}(320 \mathrm{~K})$. This is the result of internal leaks caused damages precision elements. The return dosage temperature increased about $87 \%$ by system pressure $160 \mathrm{MPa}$. For lower pressures $80 \mathrm{MPa}$ temperature increased about $40 \%$.

Figure 13 and 14 show damages precision elements. There are noticeable a lot of pollutants, metal filings, corrosion, temperature damages and pieces of fuel filter. Metal fillings come from fuel injection pump. In this case diagnostic process was very easy. Everything were visible. But sometimes there are instances where theoretical all elements are in norms but injector leaks. Using infrared camera to find this area is very helpful. There were researched injection fuel temperature on the test bench and fuel return dosages temperature for good working and faulty injectors. Injection temperatures were similar for both but return various due to leaks. The measurements have been carried starting through $40^{\circ} \mathrm{C}$ intake fuel to injectors. Than has been made one fuel injectors standard test to stabilize the temperature inside. After the test is it possible to make researches by using infrared camera. There is possibility to use this method to all modern fuel injectors. Every electromagnetic and piezoelectric fuel injectors start to heat during inner leaks. 


\section{Nomenclature}

CI compression ignition

$\mu$ micro seconds

CR common rail system

\section{Bibliography}

[1] AMBrozIK, A., AMBrozIK, T., ŁAGOWSKI, P. Fuel impact on emissions of harmful components of the exhaust gas from the CI engine during cold start up. Eksploatacja $i$ Niezawodnosc - Maintenance and Realiability. 2015, 17(1), 95-99.

[2] GÜNTHER, H. Common Rail - Systeme in der Werkstattpraxis. Technik, Prüfung, Diagnose. Bad Wörihofen: KrafthandVerlag Walter Schultz GmbH. 2012.

[3] KNEFEL, T. Ocena techniczna wtryskiwaczy Common Rail na podstawie doświadczalnych badań przelewów. Eksploatacja i Niezawodnosc - Maintenance and Reliability. 2012, 14(1), 42-53.

Tomasz Osipowicz, DEng. - Faculty of Mechanical Engineering and Mechatronics at West Pomeranian University of Technology.

e-mail:Tomasz.Osipowicz@zut.edu.pl
[4] OSIPOWICZ, T., ABRAMEK, K.F., STOECK, T. Testing of modern common rail fuel injectors. Combustion Engines. 2015, 162(3), 688-694.

[5] OSIPOWICZ, T. Diagnosing Common Rail fuel injectors using fuel micro - doses. Teka. Commission of Motorization and Energetics in Agriculture. 2015, 15(1), 61-64.

[6] OSIPOWICZ, T. Analysis of the costs and cost - efficiency of regeneration of modern fuel injection systems in CI engines. Econtechmod. An International Quarterly Journal. 2016, 5(2), 45-50.

[7] WIĘCEK, B., DE MEY, G. Termowizja w podczerwieni. Podstawy i zastosowania. Wydawnictwo PAK. 2011.

Karol F. Abramek, DSc., DEng. - Faculty of Mechanical Engineering and Mechatronics at West Pomeranian University of Technology.

e-mail:Karol.Abramek@zut.edu.pl 